\title{
Diseño y construcción de un riel electromecánico para el estudio de la cinemática de imágenes con difuminación lineal uniforme
}

\section{Design and construction of an electromechanical slider for the kinematic study of linear motion blurred images}

\author{
DOI: http://doi.org/10.17981/ingecuc.16.1.2020.06 \\ Artículo de Investigación Científica. Fecha de Recepción: 22/02/2019. Fecha de Aceptación: 23/08/2019 \\ Jimmy Alexander Cortés Osorio \\ Universidad Tecnológica de Pereira. Pereira (Colombia) \\ jacoper@utp.edu.co \\ Deivy Alejandro Muñoz Acosta (1) \\ Universidad Tecnológica de Pereira. Pereira (Colombia) \\ alejandro2460@utp.edu.co \\ Cristian David López Robayo \\ Universidad Tecnológica de Pereira. Pereira (Colombia) \\ crdalopez@utp.edu.co \\ J. Cortés Osorio, D. Muñoz Acosta y C. López Robayo, "Diseño y construcción de un riel electromecánico para el estudio de la cinemática de imágenes con \\ difuminación lineal uniforme”, INGE CUC, vol. 16, no. 1, pp. 80-94, 2020. DOI: http://doi.org/10.17981/ingecuc.16.1.2020.06
}

Para citar este artículo:

\begin{abstract}
Resumen
Introducción- En este artículo se presenta el diseño y la construcción de un riel electromecánico que permite obtener la velocidad y aceleración instantáneas de una plataforma que soporta una cámara científica al momento de la captura de la imagen, para el estudio de las imágenes difuminadas por movimiento uniforme (Motion blur). Se presentan los requerimientos de diseño mecánico y eléctrico basados en las condiciones de presentación del fenómeno. Seguido, el sistema fue calibrado con respecto a un instrumento patrón para el cálculo de incertidumbres y error.

Objetivo- En este artículo se presenta el diseño, construcción y calibración de un sistema electromecánico para el estudio de las imágenes con difuminación uniforme.

Metodología- El desarrollo del sistema se dividió en los siguientes pasos: El diseño y la construcción de un riel electromecánico en aluminio con una plataforma móvil de velocidad constante; la calibración de la velocidad de la plataforma móvil utilizando la Guía para la estimar la incertidumbre de la medición (GUM); y el diseño y la construcción de un riel electromecánico en aluminio con una plataforma móvil de aceleración constante y calibración de la aceleración de la plataforma móvil utilizando la Guía para la estimar la incertidumbre de la medición (GUM).

Resultados- Se obtuvieron incertidumbres máximas de para la velocidad y de para la aceleración del sistema.

Conclusiones- El sistema desarrollado corresponde a un sistema electromecánico que permite desplazar una plataforma con cámara a lo largo de un par de barras paralelas, de baja incertidumbre con la posibilidad de medir la velocidad y aceleración instantáneas para el estudio de imágenes reales con difuminadas por movimiento uniforme y la enseñanza de física básica.
\end{abstract}

Palabras clave- Cinemática; máquinas electrónicas; metrología; prototipo; riel

\begin{abstract}
Introduction- This paper introduces the design and the construction of an electromechanical slider that allows obtaining the instantaneous speed and acceleration of a platform that holds a scientific camera to take photos for the study motion-blurred images. The mechanical and electrical design requirements are given based on the conditions of presentation of the phenomenon. The system was calibrated concerning a standard instrument for the estimation of the uncertainty and error.
\end{abstract}

Objective- In this paper, the design, construction and calibration of an electromechanical system for the study of images with uniform motion blur is presented.

Methodology- The development of the system is split into the following steps: The design and construction of an aluminum electromechanical slider built with a mobile platform that moves at constant speed; the calibration of the speed of the mobile platform using the Guide to Estimate Uncertainty in the Measurement (GUM); and the design and construction of the electromechanical aluminum slider mounted with a mobile platform at constant acceleration and the calibration of the mobile platform for the acceleration applying the Guide for Estimation of Measurement Uncertainty (GUM).

Results-Maximum uncertainties of were obtained for speed and for acceleration of the system.

Conclusions- The developed system corresponds to an electromechanical system that allows to move a cart along a pair of parallel bars, of low uncertainty with the possibility of measuring instantaneous speed and acceleration for the study of motion blurred images and teaching of motion physics.

Keywords-Slider; electronic machines; metrology; kinematics; prototype 


\section{INTRODUCCIÓN}

En el área del procesamiento digital de imágenes, es frecuente encontrar diferentes tipos de degradaciones que afectan su análisis, tales como: las aberraciones de las lentes, la difracción de la luz, las perturbaciones atmosféricas y la difuminación causada por el movimiento (Motion Blur). Esta última se origina por el movimiento relativo entre la cámara y el objeto observado, por el temblor en las manos, por el sistema de visión del robot en movimiento, o por el desplazamiento del sistema de captura durante el tiempo de exposición. Una de las áreas de estudio de la difuminación causada por movimiento se encuentra la estimación de su Función de Punto de Dispersión (PSF) para poder reconstruir la imagen. A esta PSF se le conoce como la función de transferencia del sistema óptico y es la responsable de la difuminación [1]. En el trabajo presentado por Klyuvak, Kliuva and Skrynkovskyy [2] realizaron la estimación de la PSF de un objeto y su fondo para luego realizar una reconstrucción de la imagen. Por otro lado, Zhang, et al. [3] efectuaron un método para el cálculo de la PSF a partir de su modelo paramétrico, logrando reconstruir las imágenes originales con pocos "artefactos". El problema fundamental de este tipo de trabajos es que la difuminación por movimiento se realiza de forma sintética, es decir, que se utiliza la función matemática para generarlo. Lo anterior, provoca que los resultados se destaquen porque carecen del efecto de los fenómenos ópticos reales sobre las imágenes capturadas tales como ruido provocado por otras fuentes de luz o la lente. Otra de las áreas de estudio de la difuminación por movimiento es la estimación de velocidades a partir de una imagen usando los parámetros de la PSF, como lo demuestran $\mathrm{Lin}$ y $\mathrm{Li}$ [4]-[5], quienes presentaron una metodología para calcular la velocidad de un objeto móvil a partir de una cámara y una imagen difuminada, obteniendo resultados menores al 10\% para la velocidad, y sin embargo, no mencionan el sistema que utilizaron para captura y medir la velocidad del objeto móvil.

Basados en los anteriores trabajos [4]-[5], Mohammadi, Akbari and haghighat [6] utilizaron el dominio de la frecuencia para identificar la PSF y así determinar los parámetros de la difuminación, y de esta manera, los investigadores reportaron un error en la estimación de la velocidad inferior al 8.5\%. A diferencia de los estudios en los cuales se basaron [4]-[5], se utilizó un vehículo con una velocidad de $40 \mathrm{Km} / \mathrm{h}$; el problema de esta aproximación es la falta de evidencia de ningún tipo de proceso metrológico que permitiera confiar en la velocidad real del auto. Por lo anterior, se evidencia que en estas investigaciones las estimaciones de las cantidades cinemáticas a partir de imágenes son un tema de creciente interés, pero las propuestas de los diferentes investigadores no logran dar certeza de sus resultados, ya que no son claros con respecto a las validaciones metrológicas utilizadas.

Aunque, hoy en día ya existen sistemas que permiten conocer la velocidad y la aceleración de objetos, no hay ningún sistema comercial capaz de realizar la captura de imágenes y al mismo tiempo dar a conocer sus valores de velocidad o aceleración. Debido a la falta de un sistema integral de captura y medición para el estudio de imágenes con difuminación en este artículo se presentan los resultados del diseño y construcción un sistema mecatrónico de riel controlado para la captura de imágenes con difuminación uniforme, el cual permite conocer la velocidad y la aceleración instantánea en el punto donde se toma la imagen.

Los sistemas mecatrónicos o sistemas robóticos son utilizados hoy en día tanto en la industria como en la academia para el desarrollo de nuevas tecnologías. Para el año 2013 en la Universidad Militar Nueva Granada (Colombia) empezaron a implementar el control de un robot humanoide por medio de visión de máquina que replicaba los movimientos humanos y utilizaba un sistema de captura de movimiento antropomórfico basado en el dispositivo Kinect para realizar el movimiento imitativo de un robot Bioloid [7]. En la Universidad de Pamplona (Colombia) diseñaron y construyeron un módulo robótico para la clasificación de lulos, utilizando un brazo robótico con 5 grados de libertad y visión artificial para el reconocimiento de los frutos [8]. Posteriormente, en la Universidad de Ibagué realizaron el diseño y la construcción de un prototipo electromecánico que permitía emular los movimientos del brazo humano con un total de 13 grados de libertad. El prototipo final tuvo 5 dedos con dos grados de libertad cada uno, movimiento de giro de la muñeca, flexión de codo y movimiento completo del hombro [9]. En 2017, Londoño, Cortes y Fernández desarrollaron un sistema 
electromecánico de bajo costo para la enseñanza del movimiento rectilíneo en entorno de laboratorio [10] evidenciando que los sistemas electromecánicos tienen aplicaciones importantes en la academia para la enseñanza de la física básica y la investigación.

En el mercado se encuentran diferentes sistemas de rieles con velocidad constante para la captura de imágenes, y algunos presentan dos rieles motorizados con tracción por correa y motores paso a paso [11], [12]; sin embargo, estos sistemas no cuentan con una repetibilidad para las diferentes velocidades debido a que se maneja a través de un potenciómetro, su rango de velocidades es limitado y la velocidad máxima alcanzada no es suficiente para realizar estudios como para el presente trabajo. Por lo anterior, algunos autores han desarrollado sus propios sistemas para el estudio de imágenes con difuminación uniforme. En 2005, Pérez y Rodríguez [13] presentaron un estudio de restauración de imágenes desenfocadas por movimiento lineal uniforme y movimiento uniformemente acelerado, mencionando en su trabajo el uso de un riel de aire sin fricción para capturar las imágenes. Schuon y Diepold [14] realizaron un estudio que comparaba los algoritmos para restaurar imágenes desenfocadas sintéticamente e imágenes con desenfoque real, y para poder probar los algoritmos en imágenes desenfocadas construyeron un prototipo de captura; en la construcción utilizaron un riel para guiar el movimiento y un motor paso a paso, y cuando la cámara alcanzaba una velocidad constante, se realizaba la captura de las imágenes con un tiempo de exposición constante de 100 ms. Para 2010, Ding, McCloskey y Yu [15] hicieron un análisis del desenfoque con una cámara Flutter Shutter para movimiento no lineal, utilizando un sistema de movimiento para la captura de las imágenes, con una cámara fija donde la imagen a capturar es la que presenta el movimiento, además mencionan que utilizaron varias velocidades controladas por cambios en el voltaje de un motor para las aceleraciones constantes y haciendo uso de la gravedad lanzando un objeto que tira del móvil. Dwicahya, Ramadijanti y Basuki [16] propusieron un método para detectar la velocidad de un objeto móvil, desarrollando su propio dispositivo y compararon los resultados teóricos con los valores arrojados por el sistema para la velocidad, mecanismo que desarrollado por los investigadores alcanza velocidades hasta de $33 \mathrm{~km} / \mathrm{h}$, pero no realizaron ningún tipo de calibración, no son claros con respecto a la metodología que utilizaron para fabricar el instrumento y tuvieron problemas con el uso frecuente del prototipo. Finalmente, es de resaltar que los investigadores que han realizado diseño de los equipos desarrollados en la literatura científica no estimaron la incertidumbre y el error. El trabajo presentado en este artículo se diferencia, entre otros aspectos, por el rigor en la calibración para la estimación de la incertidumbre, el error de las medidas y la poca dispersión de los datos de velocidad y aceleración del sistema construido.

Cabe aclara que para esta investigación se entiende como cinemática el estudio del movimiento sin tener en cuenta las causas que lo provocan, tales como el desplazamiento, trayectoria, velocidad o aceleración, entre otras [17]. En este caso, el prototipo construido permitió realizar un análisis cinemático del movimiento, ya que se midieron las cantidades cinemáticas que ocurrieron en la trayectoria del móvil.

\section{Metodología}

Debido a la inexistencia en el mercado de dispositivos que permitan conocer la velocidad y aceleración de la cámara móvil, se da la necesidad de desarrollar un riel controlado para el estudio de imágenes con difuminación uniforme. En todo sistema electromecánico es necesario tener un conjunto de requerimientos para el sistema mecánico, al ser el encargado de soportar la masa de la cámara, los desplazamientos, los esfuerzos y demás factores físicos que intervienen con todo el sistema. Para el desarrollo de este se tuvieron en cuenta los siguientes requerimientos de diseño:

- El sistema debe alcanzar velocidades hasta $0,65 \mathrm{~m} / \mathrm{s}$.

- La fricción debe ser reducida al mínimo.

- La plataforma móvil debe soportar como mínimo la masa de la cámara científica Basler acA2000-165 um.

- Debe tener 10 velocidades y 5 aceleraciones diferentes.

- Las diferentes velocidades y aceleraciones deben ser constantes y repetibles. 
Para dar una mejor comprensión al lector sobre el desarrollo del sistema electromecánico, se presentará la información de la siguiente forma: diseño de sistema mecánico, diseño del sistema electrónico y calibración del sistema para velocidad, luego se presentará, en el mismo orden, para el diseño correspondiente a la aceleración.

\section{A. Diseño electromecánico para velocidad}

Para la estimación de la velocidad, se fundamentó en el principio de un encoder lineal, el cual menciona que, al conocer cada cambio entre la posición y el cambio de tiempo en un intervalo de tiempo es posible conocer la velocidad en cada instante. Para ello, el instrumento posee una serie de regletas dentadas elaboradas por medio de corte láser a las que se denominaron encoder; cada una cuenta con una cantidad de 13 pines de igual ancho. Gracias a que se conoce el ancho de cada pin $(\Delta x)$, es posible determinar el desplazamiento del objeto móvil en un intervalo con la suma de todos los $\Delta x$. Adicionalmente, el sistema registra el tiempo que tardó cada pin en pasar sobre el sensor de barrera $(\Delta t)$. Al igual que el desplazamiento, la suma de todos los $\Delta t$ determinan el tiempo que tardó el objeto en pasar sobre todo el intervalo medido. Finalmente, si la relación entre $x$ y $t$ es directamente proporcional, los puntos generan una línea recta, siendo la pendiente de esta recta la velocidad del objeto en el intervalo medido. En la Fig. 1 se puede apreciar la relación entre los $\Delta t$ y los $\Delta x$.

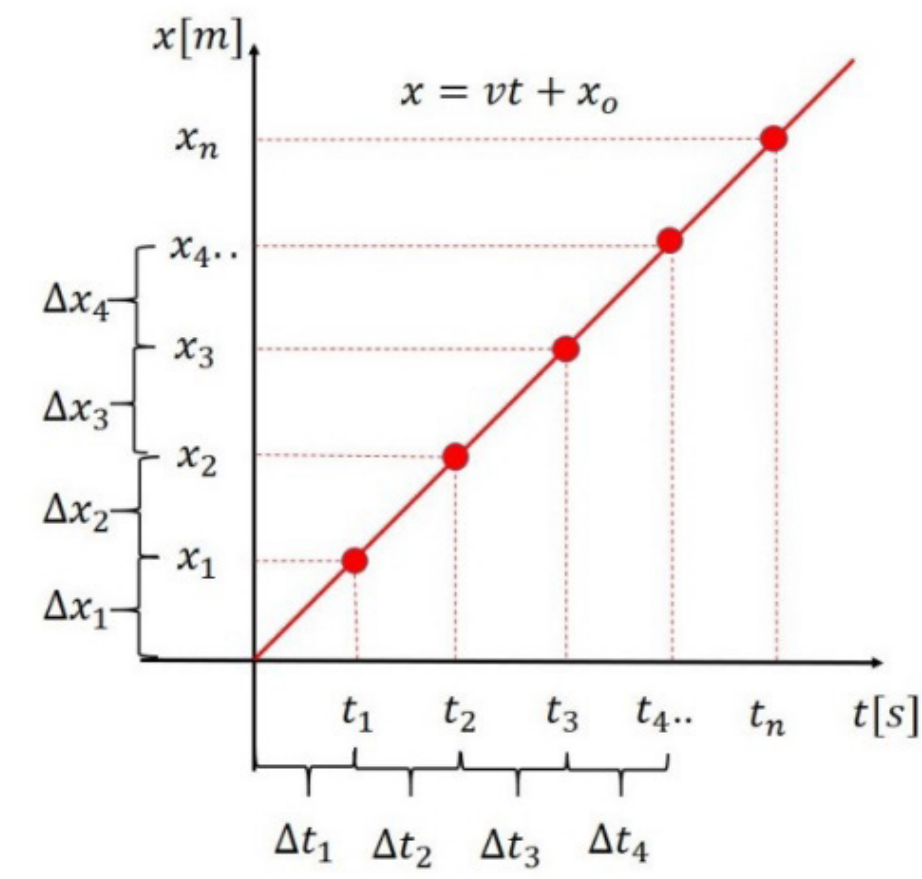

Fig. 1. Gráfica de tiempo contra distancia con una velocidad constante. Fuente: Autores.

\section{1) Diseño mecánico}

Para la construcción del riel se tuvieron en cuenta varios requerimientos de diseño, entre ellos esta que la fricción entre la plataforma móvil y los rieles fuera mínima, la capacidad de carga de la plataforma móvil y la velocidad constante que debía alcanzar. En principio se planteó un sistema con un mecanismo de tornillo sin fin por su precisión, sin embargo, este sistema no contaba con la velocidad suficiente para garantizar la presencia de la difuminación en la imagen. Por otro lado, se realizaron pruebas con un sistema de polea y contrapesos en caída libre, siendo su problema principal el hecho que no garantiza una velocidad constante en todo su trayecto. Si bien es posible construir levitadores magnéticos o neumáticos, estos agregan inestabilidad en los ejes de rotación de la plataforma móvil en donde se ubica la cámara, además se encontraban fuera del alcance económico de la presente investigación. Finalmente, se planteó un montaje mecánico de dos ejes de $12 \mathrm{~mm}$ de diámetro con rodamientos lineales que procuran la reducción de la fricción, y con una correa dentada impulsada por un motor DC con el cual se pueden programar velocidades dependiendo del voltaje sobre el motor. Partiendo de lo anterior, se realizó el diseño mostrado en la Fig. 2. 


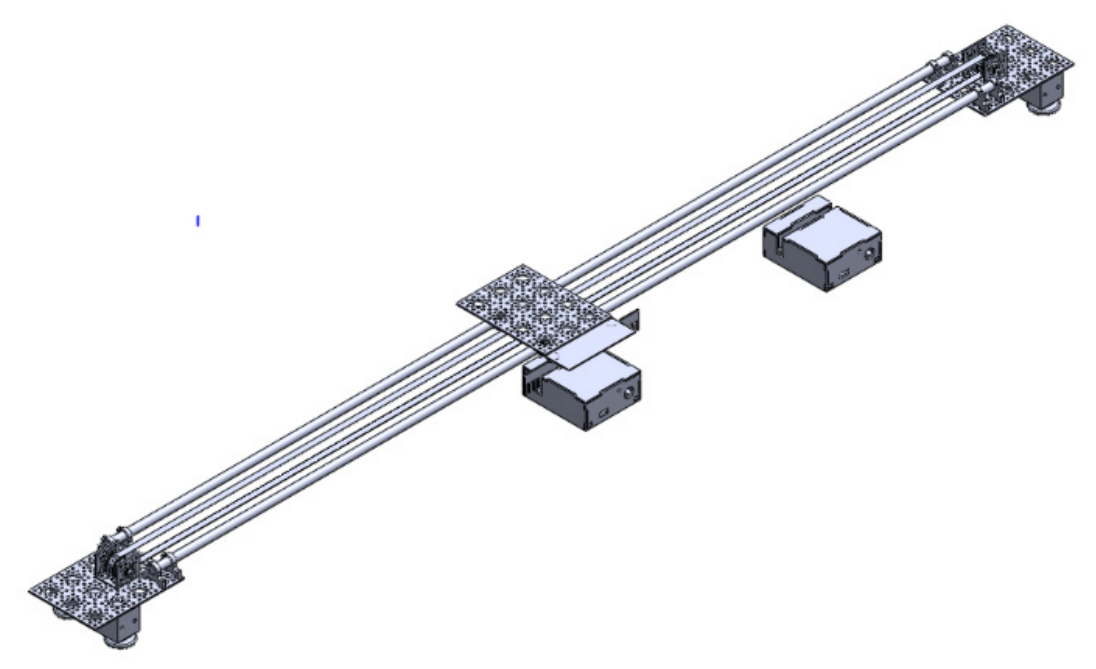

Fig. 2. Plataforma móvil sobre riel de $12 \mathrm{~mm}$ con el soporte para encoder. Fuente: Autores.

Para la selección del motor se tuvieron en cuenta dos aspectos, la velocidad lineal y el torque necesario para mover la plataforma móvil. Partiendo de la velocidad lineal requerida de $0,650 \mathrm{~m} / \mathrm{s}$, el radio del piñón de 0,012 $\mathrm{m}$ y utilizando (1) se calcularon las rpm necesarias.

$$
\begin{aligned}
& r p m=\frac{v}{r} \frac{60}{2 \pi} \\
& r p m=\frac{0,65 m / s}{0,012 m} \frac{60}{2 \pi}=517,253 \mathrm{rpm}
\end{aligned}
$$

Donde $v$ es la velocidad y $r$ es el radio del piñón. El motor seleccionado fue el Pololu 37Dx68L, el cual cuenta con un torque de $6 \mathrm{~kg}$-cm y 500 RPM máximas, suficiente para tirar de la masa de la cámara y la plataforma soporte hecha en aluminio. Si bien el motor seleccionado no alcanza las revoluciones calculadas (1), se trabajó con este debido a que, al momento del desarrollo del presente trabajo, era el más cercano al valor calculado y no se encontraron motores de marcas reconocidas y confiables, superiores a 500 RPM con el torque necesario.

\section{Diseño electrónico}

En esta sección se presenta el diseño electrónico de las etapas de control, medida y disparador. La Fig. 3 muestra el diagrama esquemático de la unidad de control general del riel.
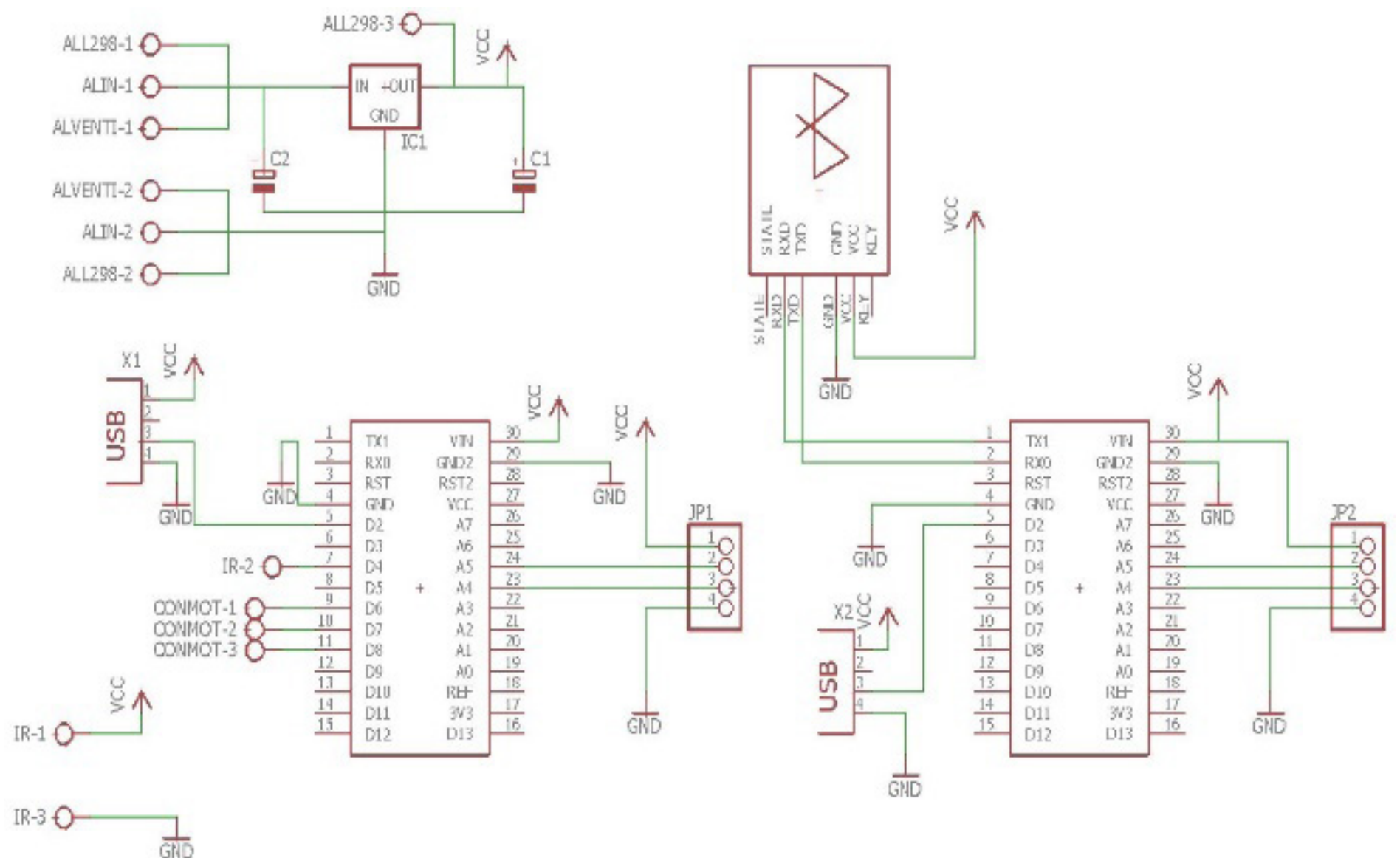

Fig. 3. Diagrama esquemático del sistema de control general. Fuente: Autores. 


\section{3) Sistema de control de velocidad}

Para controlar las diferentes velocidades se utilizó un ATmega 328P, que fue programado por medio del entorno de Arduino. Este microcontrolador fue escogido para realizar el control de velocidades por poseer contadores y temporizadores asistidos por cristales de cuarzo que le brindan una alta exactitud, adicionalmente a su ágil programación. El sistema recibe comandos por medio de un control remoto a través de un sensor infrarrojo, una vez llega el comando, el microcontrolador genera un valor de PWM (Pulse-Width Modulation) para cada una de las velocidades, que a su vez se conecta con el controlador de potencia L298N, el cual es el encargado de enviar los pulso al motor. Adicionalmente, el microcontrolador muestra en un display LCD 16 x 2 (Liquid Cristal Display) el identificador de cada una de las velocidades. Cuando el sistema detecta que el objeto móvil pasó por el final de carrera, este desactiva la señal PWM de forma inmediata para frenar el avance y evitar que la plataforma móvil choque contra el extremo del sistema.

\section{4) Sistema de medida de tiempo}

Para realizar la medida de tiempo se diseñó un circuito con el sensor de barrera "SHARP GP1A57HRJ00F”. Éste se seleccionó debido a su rápido tiempo de respuesta al cambio de estado (Bajo-Alto y Alto-Bajo) el cual es de 0,5 us. Adicionalmente, posee una ranura de $10 \mathrm{~mm}$, lo que permite pasar el encoder sin que este choque con el sensor en forma de herradura. Para medir el tiempo que tarda cada pin en el sensor de barrera (Salida en bajo) y el tiempo que no está cubierto (Salida en alto), se utilizó nuevamente el microcontrolador ATmega 328P, aprovechando la simplicidad de programación de los temporizadores y precisión en el tiempo con respecto a otros microcontroladores evaluados. Cabe resaltar que el uso de este segundo microcontrolador facilita la programación y evita errores en la lectura del tiempo sin representar un aumento significativo en el costo de implementación. El microcontrolador que se encuentra en la unidad de control se encarga de medir el tiempo (en microsegundos) que tarda cada pin en alto y en bajo, y al final de la medida, el valor de tiempo es enviado por medio del módulo Bluethooth (HC-05) hacia el sistema de cómputo para realizar la estimación de la velocidad. Cuando el sensor de herradura detecta un pin del encoder (Salida en Bajo), la salida va hacia el disparador de la cámara para la captura de la imagen. Un circuito idéntico de control de parada está implementado al final de la carrera. La Fig. 4 muestra el diagrama esquemático del circuito de detección de los pines.

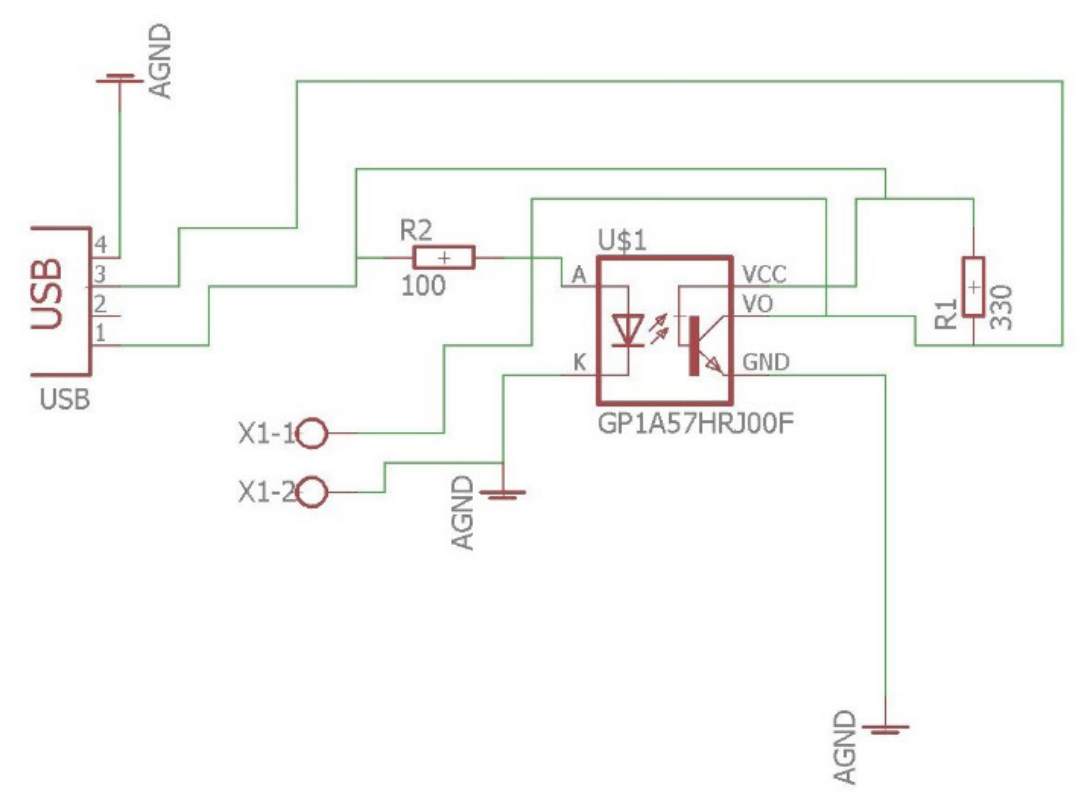

Fig. 4. Diagrama esquemático del circuito de detección de pines. Fuente: Autores.

\section{5) Interfaz de usuario}

El sistema se encarga de realizar el control de las velocidades, enviar el pulso para el disparador de la cámara y medir el tiempo en que tarda cada pin del encoder en pasar por el sensor de herradura. Hasta este punto no se ha realizado la estimación de la velocidad del objeto, esto se realizó con el fin de no sobrecargar el microcontrolador con tareas que pudieran 
impedir un correcto registro del tiempo. Para la estimación de la velocidad del objeto, se diseñó un GUIDE (Interface Gráfica de Usuario) en MATLAB 2016a; dicho programa registra los datos de tiempo enviados por la unidad de control y los computa con la información de distancia de cada uno de los pines que han sido calibrados previamente. La Fig. 5 muestra la interfaz en MATLAB 2016a.

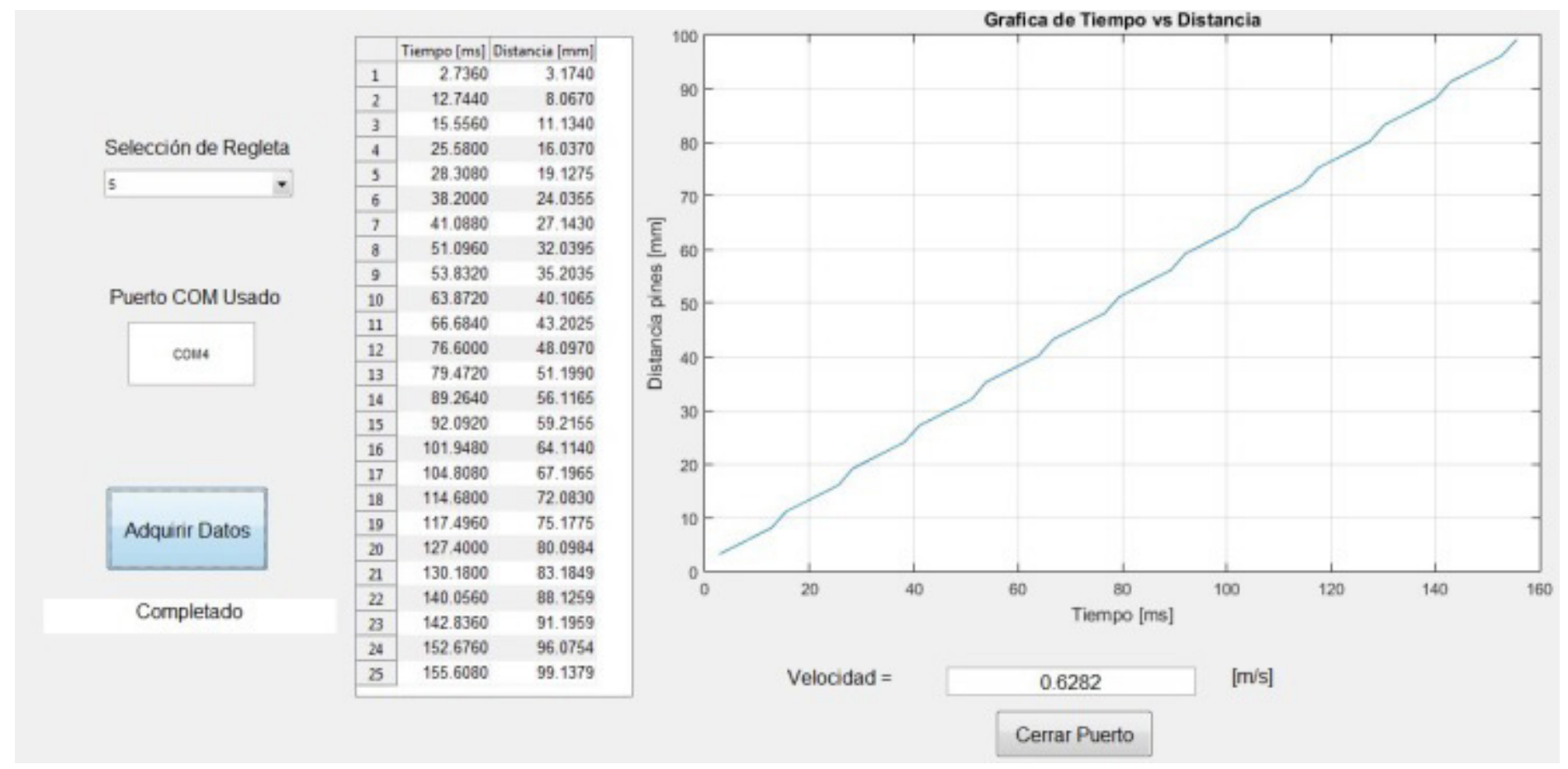

Fig. 5. Interfaz para la estimación de la velocidad en MATLAB. Fuente: Autores.

Como se conoce la distancia de cada pin del encoder y el tiempo que tarda en pasar cada pin por el sensor de herradura, la velocidad se calculó a partir de una regresión lineal del conjunto de puntos $(t, x)$. El resultado de la regresión lineal genera la ecuación de la recta de los puntos, al final, la pendiente de dicha recta es la velocidad promedio estimada del objeto móvil, tal y como se explicó en el apartado "Diseño electromecánico para la velocidad".

\section{6) Calibración para la velocidad}

El móvil representa una parte fundamental del sistema, pues su velocidad es el objeto del estudio cuando se trabaja con imágenes difuminadas por movimiento uniforme, por esta razón, se desarrolló un procedimiento de calibración, con el fin de conocer las incertidumbres de las velocidades del sistema a través de un procedimiento de medidas indirectas.

\section{- Calibración de distancia}

Debido a que el encoder representa el desplazamiento del objeto sobre el intervalo medido, es necesario conocer la distancia de cada uno de los pines de este. Para ello, se realizó la calibración de los pines con el fin de encontrar la incertidumbre correspondiente para el ancho de cada pin $(\Delta x)$. Se midió el ancho de cada pin y el ancho de cada hendidura de cada encoder con el calibrador pie de rey digital de 6 pulgadas "RM813 Ubermann". El procedimiento se realizó 20 veces por cada encoder. En la Fig. 6 se muestra el set de encoder del sistema de medida.

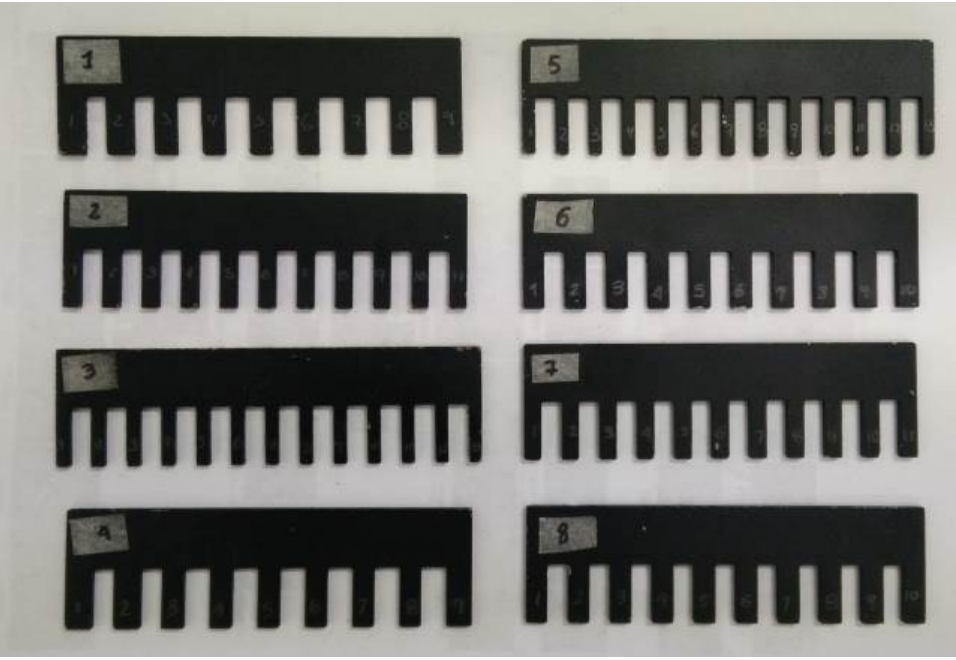

Fig. 6. Set de encoder del sistema de medida. Fuente: Autores. 
La estimación de la incertidumbre se llevó a cabo por medio de medidas directas, teniendo en cuenta los pasos básicos a seguir que expone la GUM (Guía para estimar la incertidumbre de medición) [18]. Por lo anterior, se identificaron las fuentes de incertidumbre que se muestra en la Fig. 7.

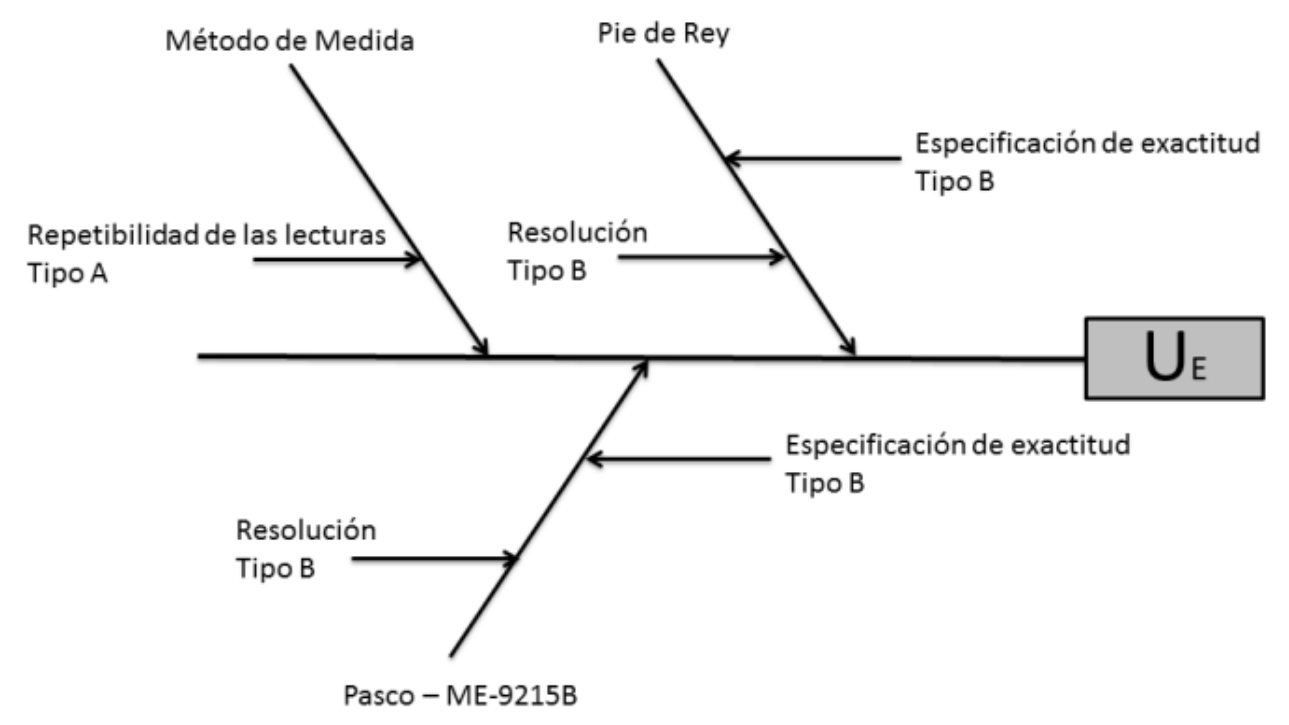

Fig. 7. Fuentes de incertidumbre de medida en el proceso de calibración. Fuente: Autores.

Luego se estimó la incertidumbre tipo A para la distancia (2).

$$
U_{A}=\frac{\sigma}{\sqrt{N}}
$$

Donde $\sigma$ es la desviación estándar del conjunto de datos y $N$ el número de mediciones. Luego se calculó la incertidumbre tipo B1 (3).

$$
\mathrm{U}_{\mathrm{B} 1}=\frac{\text { clase exactitud } \mathrm{x} \text { lectura instrumento }}{2 \sqrt{3}}
$$

La clase de exactitud es entregada por la hoja de datos del fabricante del pie de rey digital. Seguido, se calculó la incertidumbre tipo B2 (4).

$$
\mathrm{U}_{\mathrm{B} 2}=\frac{\text { Resolución del equipo }}{2 \sqrt{3}}
$$

La resolución del equipo es entregada por la hoja de datos del fabricante del pie de rey digital. Después, se calculó la incertidumbre combinada (5).

$$
\mathrm{U}_{\mathrm{c}}=\sqrt{\mathrm{U}_{\mathrm{A}}^{2}+\mathrm{U}_{\mathrm{B} 1}^{2}+\mathrm{U}_{\mathrm{B} 2}^{2}}
$$

Finalmente se calculó la incertidumbre expandida (6) con un factor de cobertura de $k=1,65$ con una distribución rectangular.

$$
\mathrm{U}_{\mathrm{E}}=\mathrm{kU}_{\mathrm{c}}
$$

\section{- Calibración de velocidad}

El procedimiento para esta calibración se realizó por medio del cálculo de incertidumbre en medidas indirectas recomendadas [18] a partir de medidas indirectas. Como la medida indirecta que se desea analizar es la velocidad $(x / t)$, se cuenta con las variables de distancia y tiempo. Debido a la dificultad y el tiempo que tomaría calibrar cada velocidad con cada encoder de forma independiente, para la medida de distancia $(\Delta x)$ se diseñó un pin de calibración con ancho 25,2 $\mathrm{mm}$. Luego se realizó el procedimiento de calibración de distancia para el pin de calibración de la Fig. 8. 


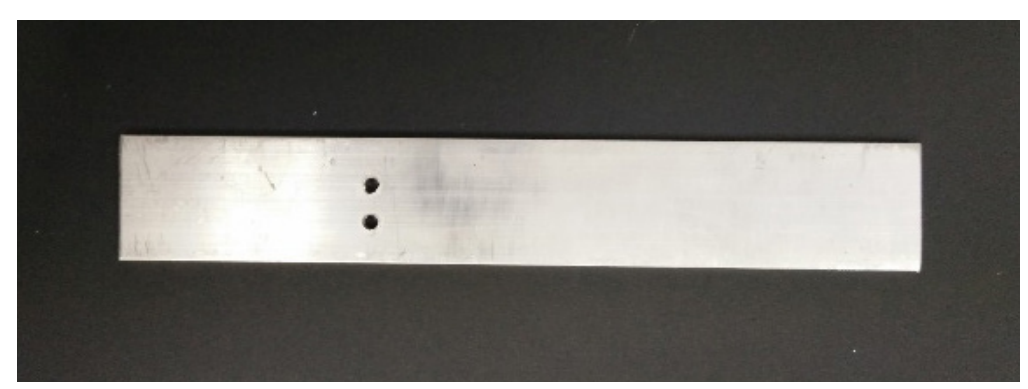

Fig. 8. Pin de calibración para el tiempo. Fuente: Autores.

Para la toma de medidas de tiempo $(\Delta t)$ se utilizaron dos sensores, los cuales tomaron 20 medidas del tiempo que tardó en cruzar el pin de calibración por los sensores para cada una de las 10 velocidades. Finalmente, se elaboró una comparación entre el instrumento patrón “Temporizador digital con barrera Infra Roja (IR) Pasco-ME-9215B” (Sensor 1) y la medida del sistema (Sensor 2). En la Fig. 9 se observa el bosquejo general de la calibración en el laboratorio.

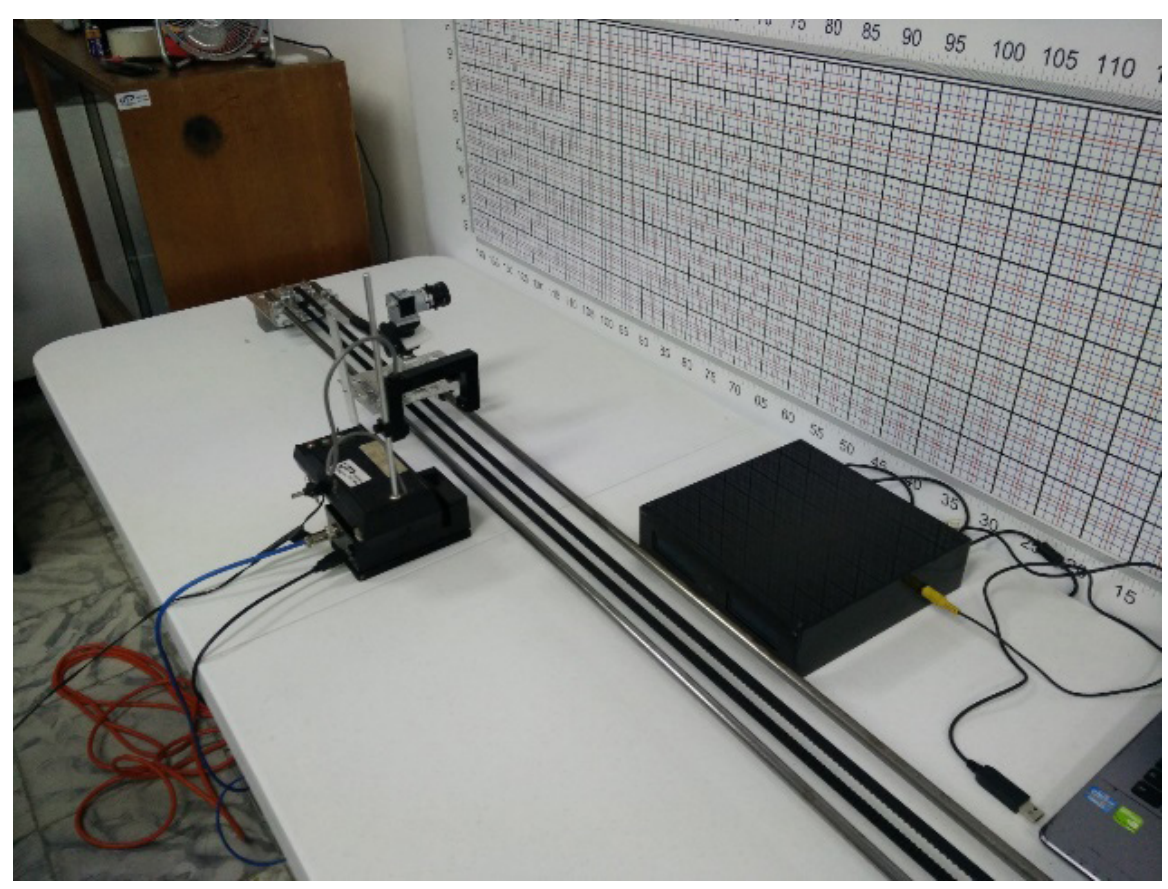

Fig. 9. Medición de tiempo con el instrumento patrón y el sistema. Fuente: Autores.

Seguido, se realizó el procedimiento de la calibración de la velocidad. Primero, se estimó la incertidumbre tipo A para el tiempo (2). A continuación, se calculó la incertidumbre tipo B1 (3). A diferencia de la calibración de la distancia, la clase de exactitud está expresada por la ecuación (7).

$$
\text { clase de exactitud }=\frac{(E c-E p)}{E p} 100
$$

Donde $E c$ es la lectura del equipo y $E p$ es la lectura del instrumento patrón. Luego se estimó la incertidumbre tipo B2 (4) con una resolución del equipo igual a $1 \times 10-6$, ya que el sistema entrega medidas de tiempo del orden de los microsegundos. Después se estimó la incertidumbre combinada (5). Como la calibración de velocidad se realizó por medio de medidas indirectas, se estimaron los coeficientes de sensibilidad (9) y (10) para cada una de las 10 velocidades. Dichos coeficientes se estimaron a partir de la función de velocidad del movimiento rectilíneo uniforme (8).

$$
v=\frac{x}{t}
$$

Donde $x$ es la distancia, $t$ es el tiempo y $v$ es la velocidad.

$$
C t=\frac{\partial f}{\partial t}=\frac{\partial}{\partial t}\left(\frac{x}{t}\right)=-\frac{x}{t^{2}}
$$




$$
C x=\frac{\partial f}{\partial x}=\frac{\partial}{\partial x}\left(\frac{x}{t}\right)=\frac{1}{t}
$$

Después se estimó la incertidumbre total (11) con los coeficientes de sensibilidad y la incertidumbre combinada de la distancia $\left(u_{\mathrm{c}}^{2}(x)\right)$ y del tiempo $\left(u_{\mathrm{c}}^{2}(t)\right)$ de cada velocidad con el pin de calibración.

$$
U_{c}(t)=\sqrt{C t^{2} u_{c}^{2}(t)+C x^{2} u_{c}^{2}(x)}
$$

Una vez estimada la incertidumbre total se utilizó el criterio de la distribución dominante, que para este caso se llamaron $U_{1}$ la incertidumbre estándar con respecto al tiempo (12) y $U_{\mathrm{R}}$ a la combinación de las incertidumbres restantes (13).

$$
\begin{aligned}
& U_{1}=\sqrt{C t^{2} u_{c}^{2}(t)} \\
& U_{R}=\sqrt{C x^{2} u_{c}^{2}(x)}
\end{aligned}
$$

Aplicando (14) se encuentra la relación entre $U_{1}$ y $U_{\mathrm{R}}$, lo que determina el tipo de distribución. Se obtuvo una relación inferior a 0,3 y por lo tanto, se siguió el procedimiento con una distribución rectangular.

$$
\frac{U_{R}}{U_{1}}=\frac{\sqrt{C x^{2} u_{c}^{2}(x)}}{\sqrt{C t^{2} u_{c}^{2}(t)}}
$$

Finalmente se estimó la incertidumbre expandida a partir de (6) con un factor de cobertura de $k=1,65$ con una distribución rectangular.

\section{B. Diseño electrónico para aceleración}

\section{1) Diseño mecánico}

Con unas pocas modificaciones en el sistema mecánico se logró pasar de velocidad constante a aceleración constante por medio del principio de plano inclinado. La idea principal fue elevar uno de los extremos y dejar que la plataforma móvil se desplazara libremente por los rieles. Cabe aclarar que la correa y el motor fueron desacoplados para no ejercer fuerzas sobre la plataforma móvil. Con el fin de elevar uno de los extremos del sistema mecánico se diseñó el soporte elevador como se muestra en la Fig. 10, el cual permitió modificar el ángulo de inclinación del sistema variando entre $2.9^{\circ}$ y $15^{\circ}$.

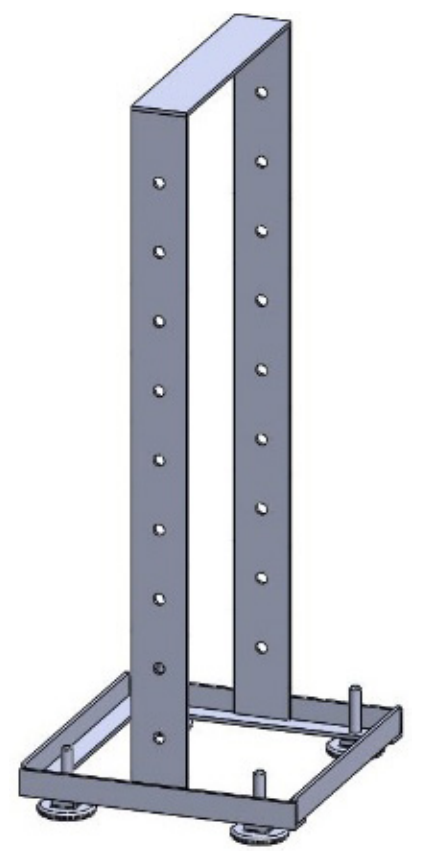

Fig. 10. Vista dimétrica del soporte elevador. Fuente: Autores. 
Al elevar todo el sistema, se presentó un inconveniente para medir los pulsos. Hasta ahora las cajas estaban apoyadas sobre la misma superficie del sistema, por lo que se diseñó un perfil en L donde se fijó el sistema de medición de pulsos. El diseño final se muestra en la Fig. 11 y se aprecia claramente un perfil en L sujetado de extremo a extremo.

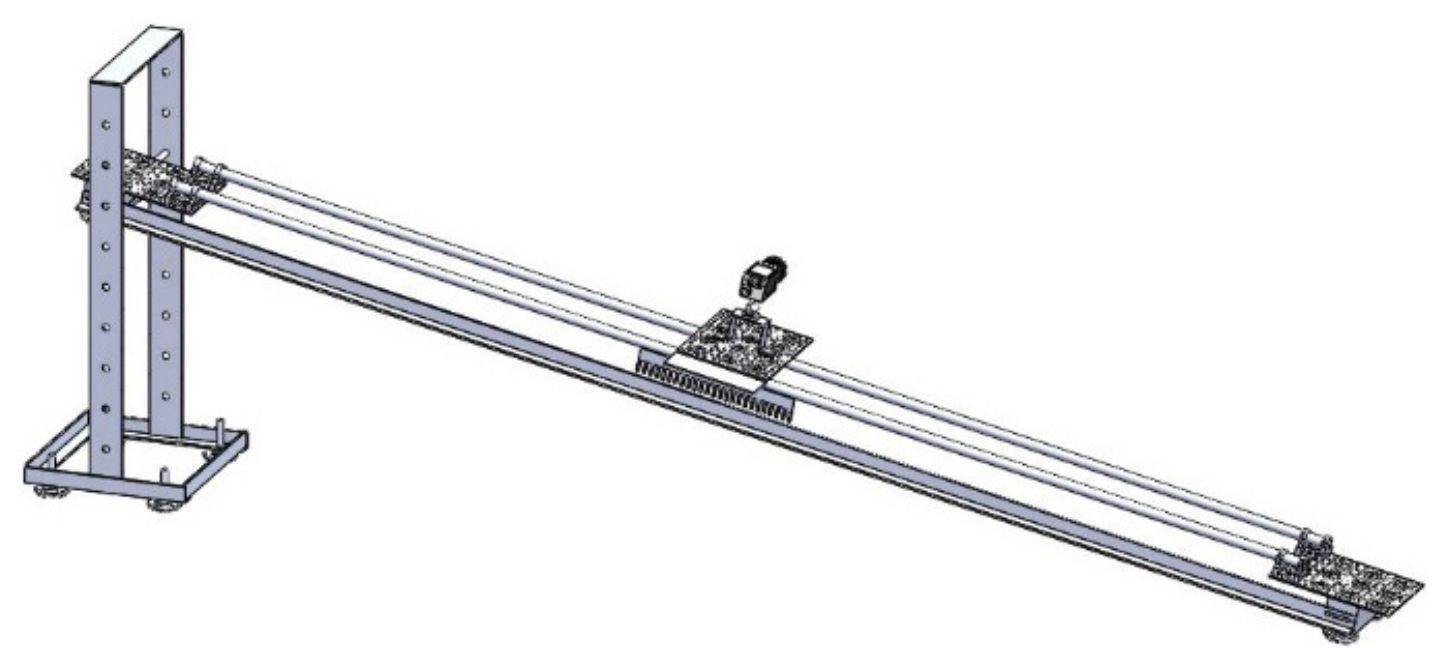

Fig. 11. Diseño final sistema mecánico de aceleración constante con vista dimétrica.

Fuente: Autores.

\section{2) Diseño electrónico}

Se realizó un nuevo diseño del circuito de pulsos disminuyendo su tamaño, haciéndolo más liviano para ser sujetado al perfil en L. Por lo que únicamente se percibe un cambio en el tamaño del circuito impreso como se observa en la Fig. 12 quedando con $6 \mathrm{~cm}$ de alto por $6 \mathrm{~cm}$ de ancho.

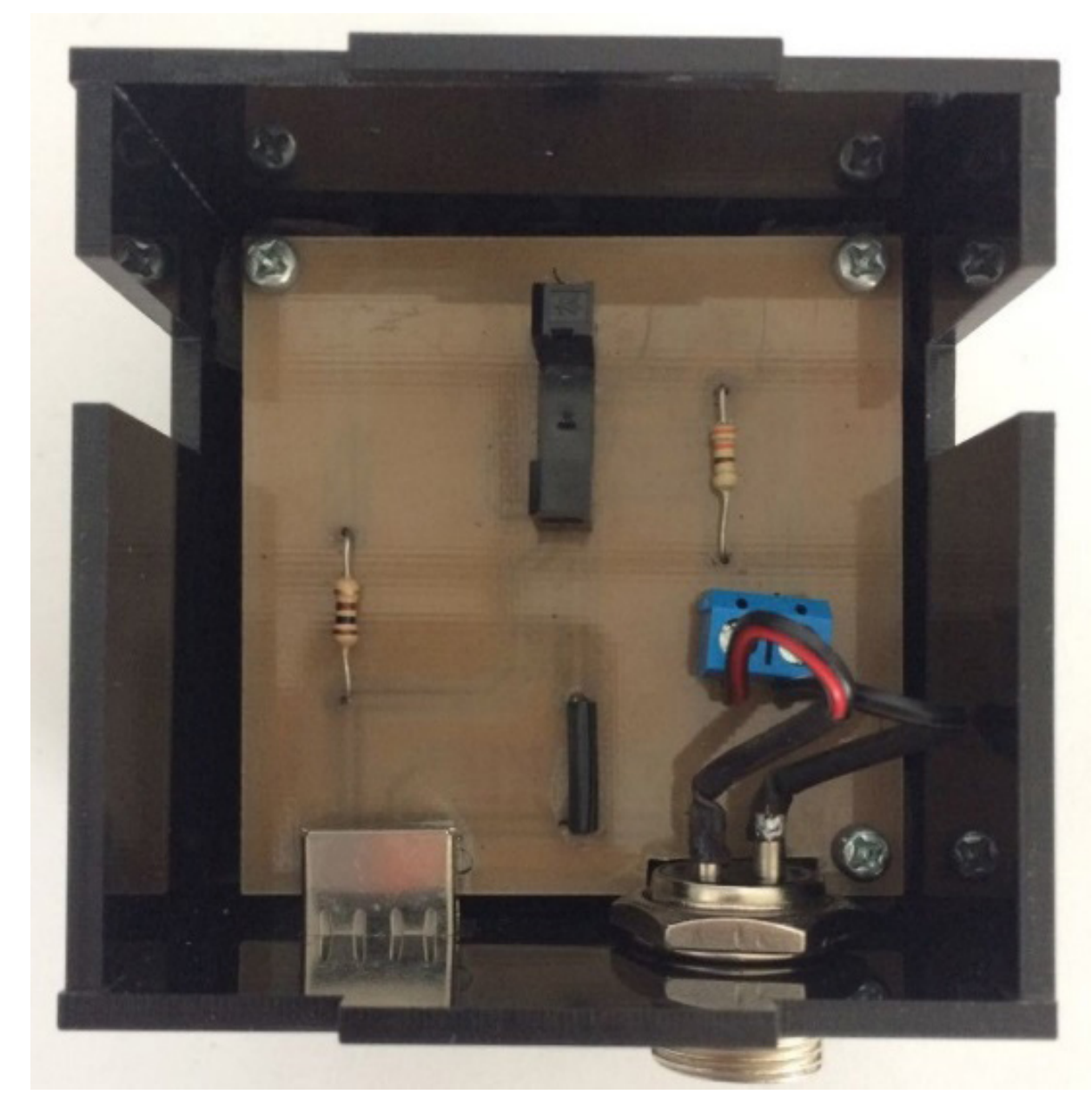

Fig. 12. Circuito detector de pines para aceleración. Fuente: Autores.

\section{3) Interfaz de usuario}

La interfaz gráfica de usuario se modificó, permitiendo elegir en qué modo trabajar, y la velocidad o aceleración. Para el caso de aceleración, se realiza una regresión polinómica de orden dos en donde el término que acompaña la variable al cuadrado corresponde a 1/2 de la aceleración de la plataforma móvil y el término que acompaña a $t$ es la velocidad inicial del sistema (Fig. 13). 

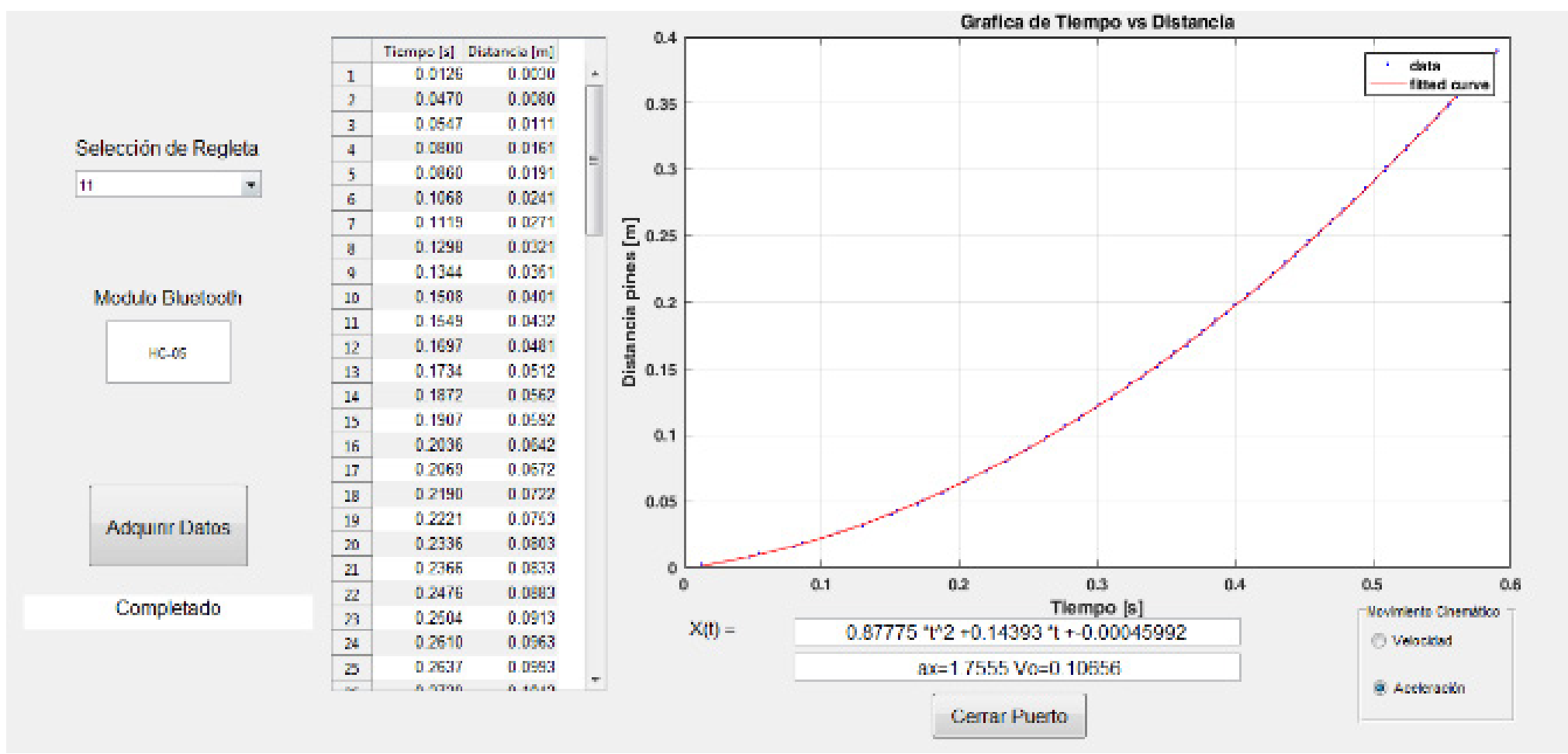

Fig. 13. Interfaz de usuario para la estimación de la aceleración en MATLAB. Fuente: Autores.

\section{4) Calibración para la aceleración}

Para la toma de medidas de aceleración se utilizaron dos sensores, los cuales tomaron 20 medidas de aceleración de acuerdo con el ángulo de inclinación (desde los $2.9^{\circ}$ hasta los $15^{\circ}$ ). Posteriormente, se elaboró una comparación entre el instrumento patrón "Phywe Cobra 4 Acceleration" (sensor 1) y la medida del sistema (sensor 2). Finalmente se realizó el mismo procedimiento de calibración de medidas directas con un instrumento patrón visto en la sección "Calibración de la distancia".

\section{Resultados}

La Fig. 14 y Fig. 15 muestran el sistema en aluminio mecanizado para las plataformas, piñones y sujeciones, además de acero calibrado $12 \mathrm{~mm} 1045$ para los ejes de desplazamiento. Todas las tarjetas fueron realizadas en el laboratorio con una máquina CNC de prototipado. De igual forma, las cajas se diseñaron mediante SolidWorks y construidas en acrílico enviadas a corte láser para ser ensambladas en el laboratorio por el grupo de trabajo. Para el sistema de tracción se utilizó una correa dentada con un paso de 0,2 pulg de neopreno con cordones de refuerzo de fibra de vidrio. Los piñones utilizados fueron de 16 dientes con el mismo paso de la correa y un diámetro de 1,25 pulg.

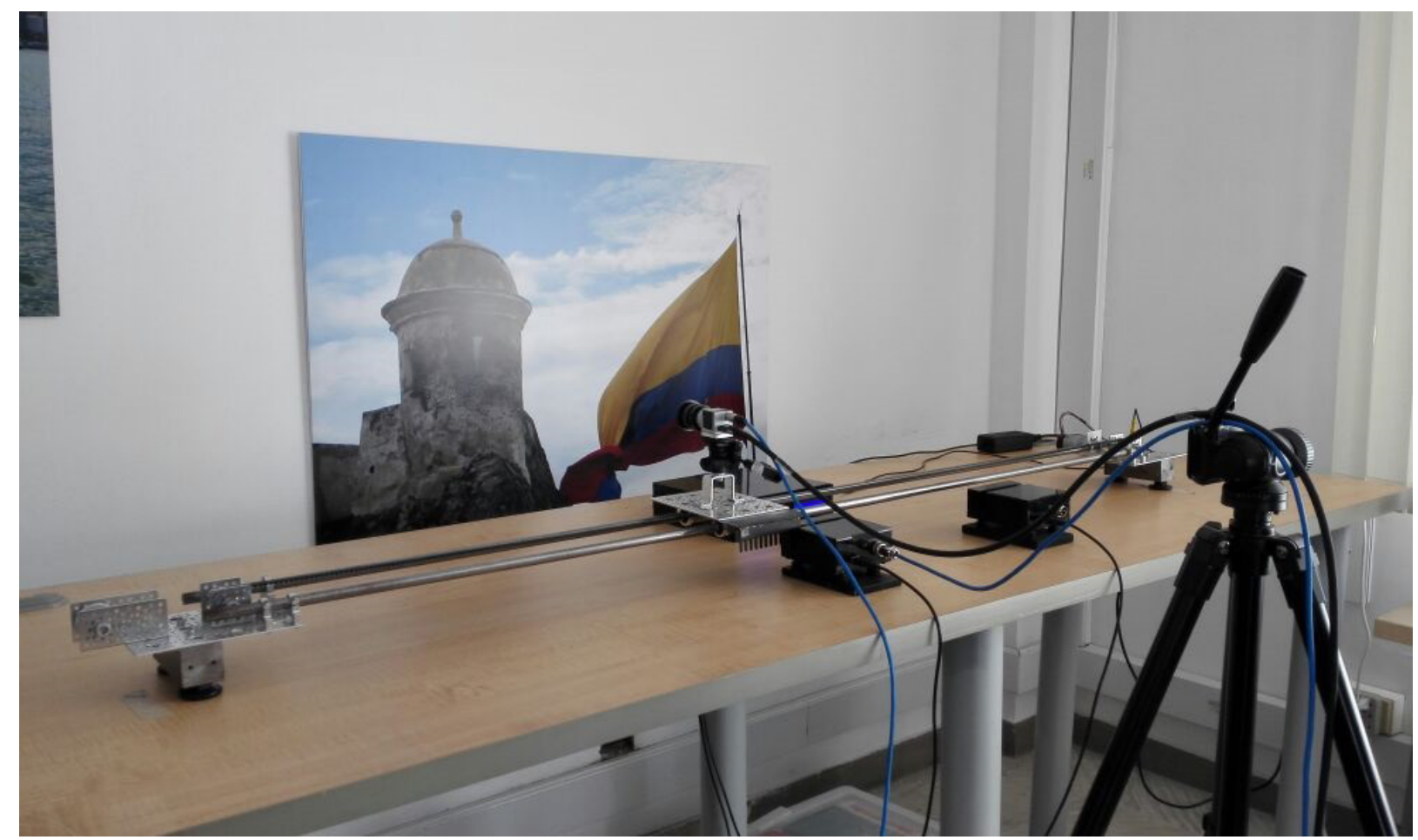

Fig. 14. Sistema electromecánico de velocidad. Fuente: Autores. 


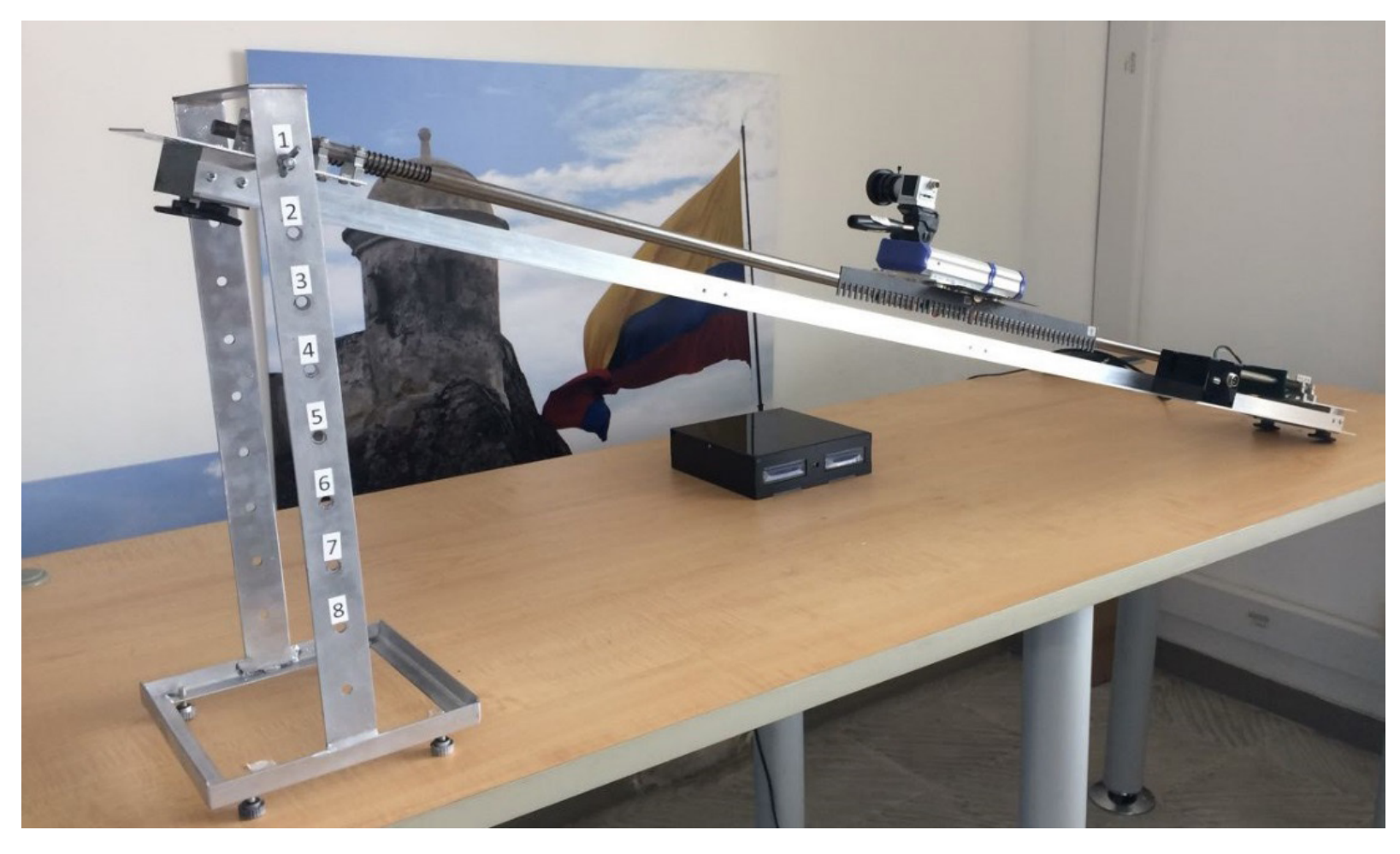

Fig. 15. Sistema electromecánico de aceleración.

$$
\text { Fuente: Autores. }
$$

La Tabla 1 muestra los primeros 5 pines y hendiduras del encoder 5 con sus respectivas medidas promedio e incertidumbres.

TABLA 1. VAlor de ALGUNos PINES DEL ENCODER CON SU CORRESPONDIENTE INCERTIDUMBRE.

\begin{tabular}{|l|l|l|}
\hline \multicolumn{1}{|c|}{ Indicador } & \multicolumn{1}{|c|}{$\mathrm{x}[\mathrm{mm}]$} & $\mathrm{X}=\mathrm{x} \pm[\mathrm{mm}]$ \\
\hline Pin 1 & 3,174 & $3,174 \pm 0,035$ \\
\hline Hendidura 1 & 4,893 & $4,893 \pm 0,038$ \\
\hline Pin 2 & 3,067 & $3,067 \pm 0,035$ \\
\hline Hendidura 2 & 4,908 & $4,908 \pm 0,036$ \\
\hline Pin 3 & 3,091 & $3,091 \pm 0,035$ \\
\hline Hendidura 3 & 4,908 & $4,908 \pm 0,035$ \\
\hline Pin 4 & 3,108 & $3,108 \pm 0,036$ \\
\hline Hendidura 4 & 4,897 & $4,897 \pm 0,037$ \\
\hline Pin 5 & 3,164 & $3,164 \pm 0,107$ \\
\hline Hendidura 5 & 4,903 & $4,903 \pm 0,036$ \\
\hline
\end{tabular}

Fuente: Autores.

Los resultados de la calibración de cada una de las 10 velocidades se muestran en la Tabla 2. Y los resultados de la calibración de cada una de las 8 aceleraciones se muestran en la Tabla 3.

TABla 2. VALOR DE LA Velocidad CON SU CORRESPONDIENTE INCERTidumbre.

\begin{tabular}{|l|l|l|}
\hline Indicador & $\mathrm{V}[\mathrm{m} / \mathrm{s}]$ & $\mathrm{V}=\mathrm{V} \pm[\mathrm{m} / \mathrm{s}]$ \\
\hline 0 & 0,173 & $0,173 \pm 0,012$ \\
\hline 1 & 0,229 & $0,229 \pm 0,016$ \\
\hline 2 & 0,324 & $0,324 \pm 0,019$ \\
\hline 3 & 0,395 & $0,395 \pm 0,022$ \\
\hline 4 & 0,457 & $0,457 \pm 0,023$ \\
\hline 5 & 0,500 & $0,500 \pm 0,025$ \\
\hline 6 & 0,533 & $0,533 \pm 0,027$ \\
\hline 7 & 0,573 & $0,573 \pm 0,028$ \\
\hline 8 & 0,591 & $0,591 \pm 0,028$ \\
\hline 9 & 0,666 & $0,666 \pm 0,031$ \\
\hline
\end{tabular}

Fuente: Autores. 
TABLA 3. VALOR DE LA ACELERACIÓN CON SU CORRESPONDIENTE INCERTIDUMBRE.

\begin{tabular}{|l|l|l|l|}
\hline Indicador & Ángulo & \multicolumn{1}{|c|}{$a\left[\mathrm{~m} / \mathrm{s}^{2}\right]$} & \multicolumn{1}{|c|}{$a=a \pm U_{\mathrm{E}}\left[\mathrm{m} / \mathrm{s}^{2}\right]$} \\
\hline 1 & $15^{\circ}$ & 2,463 & $2,463 \pm 0,029$ \\
\hline 2 & $13.3^{\circ}$ & 2,178 & $2,178 \pm 0,023$ \\
\hline 3 & $11.5^{\circ}$ & 1,863 & $1,863 \pm 0,012$ \\
\hline 4 & $10.1^{\circ}$ & 1,541 & $1,541 \pm 0,016$ \\
\hline 5 & $7.9^{\circ}$ & 1,229 & $1,229 \pm 0,013$ \\
\hline 6 & $6.1^{\circ}$ & 0,942 & $0,942 \pm 0,009$ \\
\hline 7 & $4.5^{\circ}$ & 0,644 & $0,644 \pm 0,007$ \\
\hline 8 & $2.9^{\circ}$ & 0,351 & $0,351 \pm 0,004$ \\
\hline
\end{tabular}

Fuente: Autores.

\section{CONCLusiones}

El sistema desarrollado corresponde a un sistema electromecánico que permite desplazar una plataforma a lo largo de un par de barras paralelas que soportan una cámara, con la posibilidad de medir la velocidad y aceleración instantáneas para el estudio de imágenes con difuminadas por movimiento uniforme y acelerado.

La construcción final del sistema fue calibrado con respecto a otros sistemas de medida dando como resultados incertidumbres $0,173 \pm 0,012 \mathrm{~m} / \mathrm{s}$ y $0,351 \pm 0,004$ para la velocidad y aceleración respectivamente, con lo cual se puede concluir que el sistema es confiable para el estudio del movimiento lineal uniforme y acelerado.

Debido a que el sistema tiene la capacidad de medir velocidad y aceleración instantáneas por medio de los encoders y sensores, este también puede ser usado para la enseñanza del movimiento rectilíneo uniforme y la enseñanza del plano inclinado.

En el estudio realizado en [19], fue posible obtener imágenes con difuminación uniforme con el instrumento y se obtuvieron resultados consistentes en términos de valores de velocidad estimada. En resumen, las velocidades en el estudio mediante procesamiento digital de imágenes fueron consistes (error inferior al 5\%) con las arrojadas por el sistema electromecánico.

Los resultados de uso se evidencian en el trabajo presentado por Cortés Osorio et al. en [20] donde fue usado para evaluar un método novedoso para la estimación de la velocidad de un objeto a partir de una única imagen desenfocada.

Se propone como trabajo futuro, aumentar la velocidad máxima de la plataforma móvil hasta y ampliar el rango de velocidades a 20; esto se logra cambiando el motor, y aumentando la longitud de los ejes. Lo anterior trae nuevos desafíos como son: la implementación del sistema de frenado y el tratamiento térmico de los ejes para disminuir el pandeo.

\section{Financiamiento}

Articulo derivado del proyecto de investigación "Contribución a la estimación de las cantidades cinemáticas a partir de imágenes desenfocadas por movimiento lineal uniforme”. Financiado por Vicerrectoría de Investigaciones, Innovación y Extensión, Grupo de investigación Robótica Aplicada, Universidad Tecnológica de Pereira. Fecha de inicio: enero de 2016. Fecha de finalización: enero de 2018.

\section{REFERENCIAS}

[1] J. Cortés-Osorio, C. López-Robayo, and N. Hernández_Betancourt, "Evaluation and comparison of techniques for reconstructing the point spread function of images blurred by uniform linear motion", TecnoL., vol. 21, no. 42, pp. 211-229, May. 2018. https://doi.org/10.22430/22565337.789

[2] A. Klyuvak, O. Kliuva and R. Skrynkovskyy, "Partial Motion Blur Removal," in IEEE Second International Conference, Data Stream Mining \& Processing (DSMP), Lviv, Ukraine, Oct. 21-25, 2018, pp. 483-487. https://doi.org/10.1109/DSMP.2018.8478595

[3] A. Zhang, Y. Zhu, J. Sun, M. Wang and Y. Zhang, "Parametric model for image blur kernel estimation," 2018 International Conference, Orange Technologies (ICOT), Nusa Dua, BALI, Indonesia, Oct. 23-26, 2018, pp. 1-5. https://doi.org/10.1109/ICOT.2018.8705790 
[4] H. Lin and K. Li, "Motion blur removal and its application to vehicle speed detection," 2004 International Conference on Image Processing, ICIP '04, Singapore, Singapore, Oct. 24-27, 2004, pp. 3407-3410. https://doi.org/10.1109/ICIP.2004.1421846

[5] H. Lin and K. Li, "Vehicle speed estimation from single still images based on motion blur analysis," in IAPR Conference on Machine Vision Applications, IAPR MVA 2005, Tsukuba Science City, Japan, May. 16-18, 2005, pp. 128-131.

[6] J. Mohammadi, R. Akbari and M. K. Ba haghighat, "Vehicle speed estimation based on the image motion blur using RADON transform," in 2nd International Conference on Signal Processing Systems, ICSPS 2010, Dalian, China, Jul. 5-7 2010, pp. V1-243-V1-247. https://doi.org/10.1109/ICSPS.2010.5555577

[7] R. Jiménez, F. Espinosa and D. Amaya, "Control de Movimiento de un Robot Humanoide por medio de Visión de Máquina y Réplica de Movimientos Humanos”, INGE CUC, vol. 9, no. 2, pp. 44-51, Dic. 2013. Available from https://revistascientificas.cuc.edu.co/ingecuc/article/view/5

[8] P. Contreras, C. Peña and C. Riaño, "Módulo Robótico para la Clasificación de Lulos (Solanum Quitoense) Implementando Visión Artificial”, INGE CUC, vol. 10, no. 1, pp. 51-62, Jul. 2014. https://revistascientificas.cuc.edu.co/ingecuc/article/view/343

[9] L. Gallo, M. Guerrero, J. Vásquez and M. Alonso, "Diseño de un Prototipo Electromecánico para la Emulación de los Movimientos de un Brazo humano", INGE CUC, vol. 12, no. 2, pp. 17-25, Ago. 2016. Available from https://doi.org/10.17981/ingecuc.12.2.2016.02

[10] Y. Londoño, J. A. Cortés and M. E. Fernández, "Diseño, construcción e implementación de sistema de adquisición y análisis de datos para la enseñanza del movimiento rectilíneo en el laboratorio", Momento, no. 55, pp. 57-73, Dec. 2017. https://doi.org/10.15446/mo.n55.66146

[11] "Revolve: Motorized Slider", Resolve, Seattle, WA, USA. [Online]. https://www.revolvecamera.com/products/ram-motorized-dolly-slider-bundle (accesed 28/08/2019).

[12] "Rhino Slider EVO", Rhino Camera Gear, Seattle, WA, USA. [Online]. https://rhinocameragear.com/ pages/new-to-rhino-learn-the-system (accesed 28/08/2019).

[13] J. S. Pérez and G. Rodriguez-Zurita: "Image restoration of blurring due to rectilinear motion: constant velocity and constant acceleration”, Revista mexicana de física, vol. 51, no. 4, pp. 398-406, May. 2005. Available from https://rmf.smf.mx/page/rmf-e_anteriores?volume=51

[14] S. Schuon and K. Diepold, "Comparison of motion de-blur algorithms and real-world deployment", Acta Astronautica, vol. 64, no. 11-12, pp. 1050-1065, Jun. 2009. https://doi.org/10.1016/j.actaastro.2009.01.012

[15] Y. Ding, S. McCloskey and J. Yu, "Analysis of motion blur with a flutter shutter camera for non-linear motion", in European Conference on Computer Vision, ECCV 2010, Heraklion, Crete, Greece, pp. 15-30, Sep. 5-11, 2010. https://doi.org/10.1007/978-3-642-15549-9_2

[16] J. A. Dwicahya, N. Ramadijanti and A. Basuki, "Moving Object Velocity Detection Based on Motion Blur on Photos Using Gray Level," International Electronics Symposium on Knowledge Creation and Intelligent Computing, IES-KCIC 2018, Bali, Indonesia, Oct. 29-30, 2018, pp. 19-198. https://doi.org/10.1109/ KCIC.2018.8628598

[17] J. S. Beggs. Kinematics. Boca Ratón, Fl., USA: CRC Press, 1983.

[18] W. A. Schmid and R. J. Lazos, "Guía para estimar la incertidumbre de la medición", CENAM, El Marqués, Qro, MX, Rev. 1, 2000. [Online]. Available: http://depa.fquim.unam.mx/amyd/archivero/EstimaciondelaIncertidumbre_32954.pdf

[19] J. A. Cortes-Osorio, "Evaluación y Comparación de Técnicas de Restauración de la Función de Punto de Dispersión para la Estimación de la Velocidad de un Objeto," Tesis pregado, Dept. Fís., UTP, Pereira, Risaralda, Colombia, 2017.

[20] J. A. Cortés-Osorio, J. B. Gómez-Mendoza and J. C. Riaño-Rojas, "Velocity Estimation From a Single Linear Motion Blurred Image Using Discrete Cosine Transform," IEEE Trans. Instrum. Meas., vol. 68, no. 10, pp. 1-13, Dec. 2018. https://doi.org/10.1109/TIM.2018.2882261

Jimy Alexander Cortes recibió el titulo de Ingeniería Electrica y maestría en Instrumentación Física en la Universidad Tecnológica de Pereira (Colombia). Sus investigaciones incluyen procesamiento de imágenes, análisis de imágenes en moviemiento, machine learning, instrumentación y medición. https://orcid.org/0000-0002-0413-807X.

Deivy Alejandro Muñoz Acosta es Ingeniero en Mecatrónica y magister en Instrumentación Física de la Universidad Tecnológica de Pereira (Colombia). Los campos de investigación de interés son la robótica, el procesamiento digital de imágenes y el aprendizaje de máquina. https://orcid.org/0000-0003-4743-8301

Cristian David López Robayo recibió el título de Ingeniero Electrónico de la Universidad Tecnológica de Pereira (Colombia). Se ha desempeñado como joven investigador en el grupo de Investigación Robótica aplicada desde el 2015 en el área de procesamiento digital de imágenes y aprendizaje de máquina. https://orcid.org/0000-0002-7937-4683 